\title{
METHOD OF DECISION TREE APPLIED IN ADOPTING THE DECISION FOR PROMOTING A COMPANY
}

Cezarina Adina TOFAN

Spiru Haret University, Câmpulung Muscel E-mail: cezarina_adina@yahoo.com

\begin{abstract}
The decision can be defined as the way chosen from several possible to achieve an objective. An important role in the functioning of the decisionalinformational system is held by the decision-making methods. Decision trees are proving to be very useful tools for taking financial decisions or regarding the numbers, where a large amount of complex information must be considered. They provide an effective structure in which alternative decisions and the implications of their choice can be assessed, and help to form a correct and balanced vision of the risks and rewards that may result from a certain choice. For these reasons, the content of this communication will review a series of decision-making criteria. Also, it will analyse the benefits of using the decision tree method in the decision-making process by providing a numerical example. On this basis, it can be concluded that the procedure may prove useful in making decisions for companies operating on markets where competition intensity is differentiated.
\end{abstract}

Keywords: decision, decision-making methods, decision trees, information system

JEL Classification: $\mathrm{C}_{3}, \mathrm{M}_{2}, \mathrm{~L}_{6}$

\section{Introduction}

The realities of the modern society show us that with the development of the market economy and the increase of its complexity, on needs to develop properly the economic information as well so that it can provide the necessary elements to make decisions, to be able to accurately reflect the financial situation of the economic agents and economic and financial results, the main objective being increasing the company's value.

Management, through its functions and attributes, is the one that determines the company's objectives, the resources necessary to achieve them, as well as the distributions of the results created by using these resources. The raw materials, on which the management is based on, are information and people [Tofan C.A., 2009].

The decision may be defined as the way chosen from several possible to achieve an objective. The quality and the value of decisions taken by the decisionmaking system depend on the quality of the information. The qualitative characteristics of information can be minimized by the operations to which they are 
subject, beginning from the collection, passing through processing and finishing with their transmission.

One company can calculate several types of costs, depending on its organizational choices, usefulness and their use. Basically, the costs calculated diversity shows the diversity of decisions in an organization.

The costs are calculated according to the person who uses them, to the purposes for which he uses them and the cost object. Cost object is any item (product, customer, department, activity) for which costs are measured [Tofan C.A., 2013].

A cost is relevant, if it is drawn at the right time for the right decision maker to ensure a precise and satisfactory decision.

The cost-type information is important for managers for at least three reasons [Tofan C.A., 2013]:

- based on the cost one decides the acquisition, production or abandon of a product and the nature of the customer relationship is also influenced;

- costs can be a basis for a price quote;

- the cost analysis identifies the need to improve product design or manufacturing process.

The role of the cost calculation in the management process can be summarized as follows: it allows current and strategic decision making, helps determining the analytical results and facilitates the prediction and analysis of deviations.

Among the management decisions taken based on information about the activities, there are included: review of the product price, product and customer profitability analysis, replacing or removing products, investing in technology [Tofan C.A., 2013].

\section{Theoretical background}

\section{Criteria for adopting the decision within companies}

Decisions with random universe are characterized by the following elements: factors and decisional consequences are not perfectly known, there are a multitude of consequences and a probability may be assigned to each consequence.

Probability calculation allows determining the optimal alternative that maximizes the economic function determined by the decision maker.

In this case, the decision criterion is the mathematical expectancy that applies to the repetitive decisions.

The function to calculate the mathematical expectancy of winning is calculated by using the following formula:

$$
E_{m j}=\sum_{j=1}^{n} p_{j} * R_{i j}
$$


In which:

$E_{m j}$ is the mathematical expectancy of gain for the i decision (i version)

$p_{j}$ is the probability of achieving the $\mathrm{j}$ criterion results

$R_{i j}$ symbolizes the result for $p_{j}$ probability

Within companies, the types of economic problems which have a random future are very numerous. Complex situations benefit from obtaining good results to determine the optimal decision using the decision tree method.

The decision tree is used for the complex decisions such as those for the investment optimization, assimilating in manufacturing of a new product, selling products and others.

\section{example \\ Adopting the decision using the decisional tree method - a numerical}

A company wants to set out for the next semester the sequences required for its plan of operation, carrying into effect several advertising campaigns that will be fulfilled in time for various channels (radio, television). Each new decision will be taken depending on the reaction of its main competitor.

The company may allocate its quarterly budget either for a television campaign which would cost 2,000 euros, or a radio campaign that would cost 1,000 euro.

The competitor may or may not commit an action on the same channel, which results in a variable income.

In the next quarter, the company can choose again between a radio campaign and a television campaign that would lead to new financial results due to the competitor's reaction.

The decisions, the competitor reactions, and the results (costs and gains) of each person as well as the probabilities are shown directly on the decision tree shown in Figure 1.

In this tree, the following notations are used

- roads (arcs) symbolized by a square and marked with numbers $\left(\begin{array}{lll}0 & \ldots & \ldots\end{array}\right.$ 20), corresponding to the company decisions;

- roads (arcs) symbolized by a circle and marked with letters (A, B ... J), corresponding to the interventions chance, respectively the reaction of competition;

- $\mathrm{p}=$ probability;

- $\mathrm{R}=$ net result of the decision for the period;

- TV, radio, decision alternatives of the company or of the competitors.

Based on the presented data one can determine the decision that may be taken. For this we calculated the value of each road that leads to the original decision. 


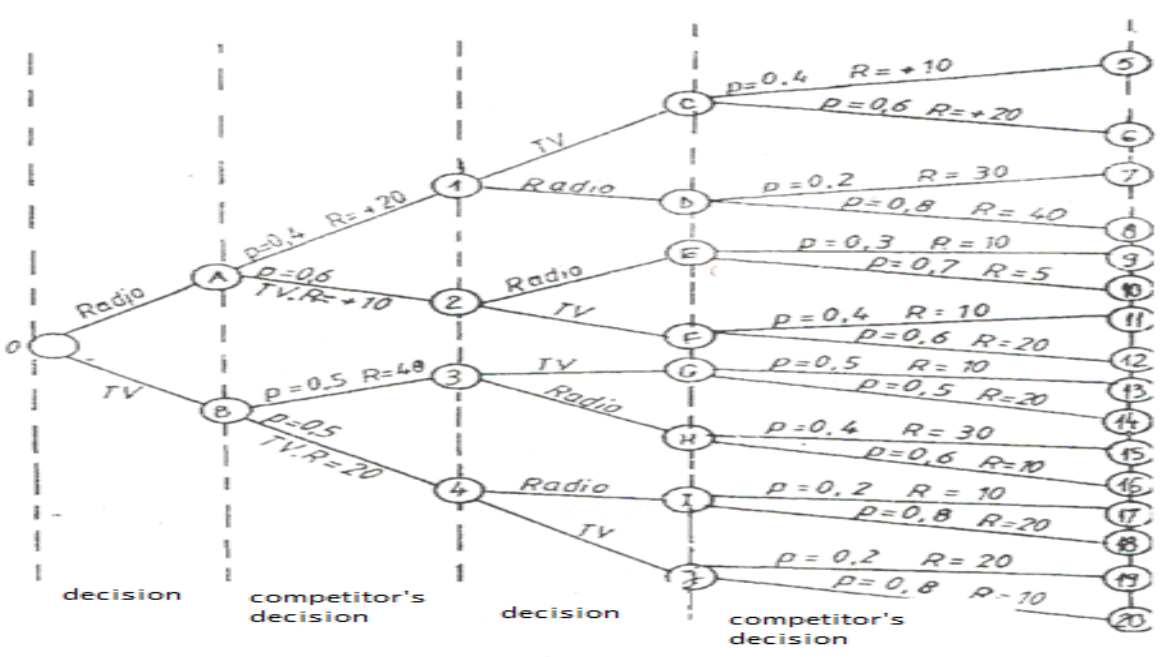

For each stage, we calculate the expectancy of gain (E) starting from the end of the graph, applying the formula (1.1):

$$
\begin{aligned}
& \mathrm{E}(\mathrm{C})=10 * 0.4+20 * 0.6=16 \\
& \mathrm{E}(\mathrm{D})=30 * 0.2+40 * 0.8=38 \\
& \mathrm{E}(\mathrm{E})=10 * 0.3+5 * 0.7=6.5 \\
& \mathrm{E}(\mathrm{F})=10 * 0.4+20 * 0.6=16 \\
& \mathrm{E}(\mathrm{G})=10 * 0.5+20 * 0.5=15 \\
& \mathrm{E}(\mathrm{H})=30 * 0.4+10 * 0.6=18 \\
& \mathrm{E}(\mathrm{I})=10 * 0.2+20 * 0.8=18 \\
& \mathrm{E}(\mathrm{J})=20 * 0.2+10 * 0.8=10
\end{aligned}
$$

After the calculations, it results that a number of roads can be removed. If the company leaves from point 1 , it is clear that we must choose the road $\mathrm{D}$ because the mathematical expectancy value is greater $38>16$. Thus, $\mathrm{C}_{5}$ and $\mathrm{C}_{6}$ are eliminated.

A similar procedure is applied to others possibilities, thus simplifying the tree. So, it results a simplified tree shown in the following figure: 
Figure no. 2. Decisional tree after eliminating some branches resulted from calculations

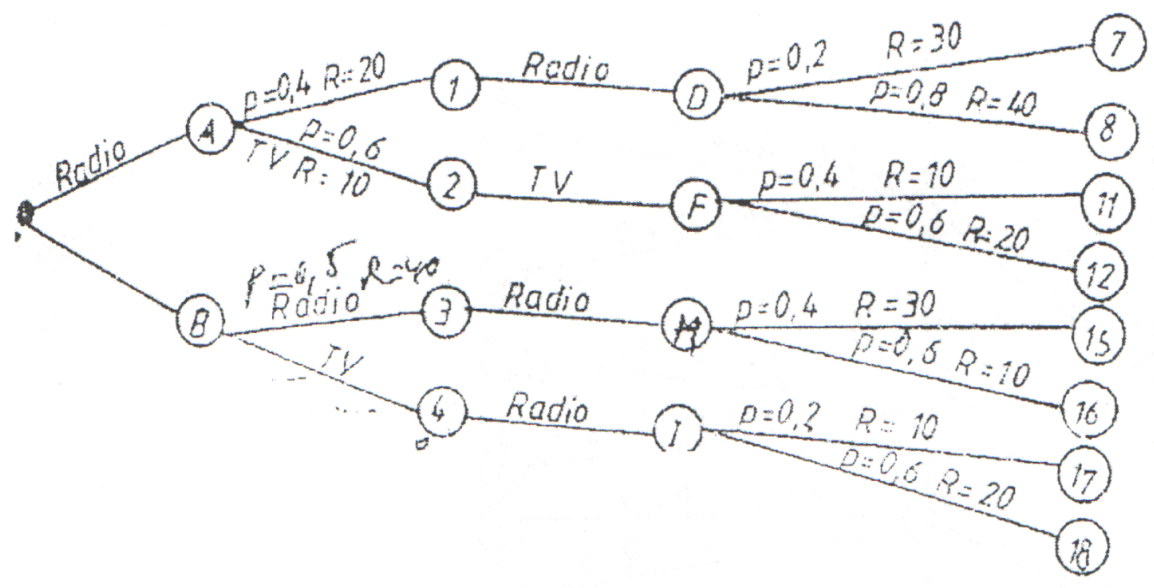

$$
\begin{aligned}
& \mathrm{E}(\mathrm{D})=30 * 0.2+40 * 0.8=38 \\
& \mathrm{E}(\mathrm{F})=10 * 0.4+20 * 0.6=16 \\
& \mathrm{E}(\mathrm{H})=30 * 0.4+10 * 0.6=18 \\
& \mathrm{E}(\mathrm{I})=10 * 0.2+20 * 0.6=18
\end{aligned}
$$

Thus, it can be calculated the expectancy of gain for every road to the end of the first period (in A and B):

$$
\begin{aligned}
& \mathrm{E}(\mathrm{A})=0.4 * \mathrm{E}(\mathrm{A}, \mathrm{D})+0.6 * \mathrm{E}(\mathrm{A}, \mathrm{F})=0.4(20+38)+0.6(10+16)=38.4 \\
& \mathrm{E}(\mathrm{B})=0.5 * \mathrm{E}(\mathrm{B}, \mathrm{H})+0.5 * \mathrm{E}(\mathrm{B}, \mathrm{I})=0.5(40+18)+0.5(20+18)=48
\end{aligned}
$$

The tree can be further simplified, resulting in the situation shown in the following figure:

Figure no. 3. Decisional tree after eliminating some branches resulted from the expectancy of gain calculations

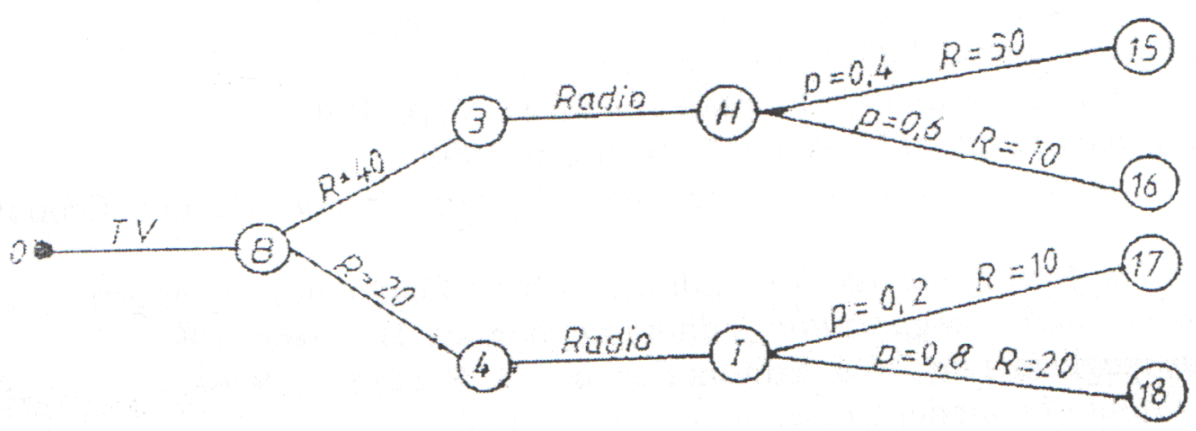


It can be concluded that the tree allows taking the first optimal decision, meaning the company must conduct a television campaign because the hope of winning is 48 to 38.4 for the radio campaign.

The following decisions are subject to competition reaction. Thus, if the competition reacts (Section 3), the company will have to fight back through a radio campaign $(3 \mathrm{H}$ road that has a value greater than $3 \mathrm{G})$. If the contestant chooses a TV campaign (point 4), now it has to fight back through a radio campaign. It follows that the company must start with a TV campaign and track with a radio campaign.

At present, the uncertain and changing environment, in which the companies operate, leads to the occurrence of many unforeseeable situations, therefore it is advisable to underlie scientifically the decisions.

The decisional tree method is applied in situations when the hazard periods (risk) succeed the decision periods, with several possible consequences, to which may be associated a probability.

The probability of the risk represents the possibility that risk to occur. According to the probability theory, it is called the probability of the event A (denoted by $\mathrm{P}(\mathrm{A})$ ) the ratio between the $m$ number of the favourable results for occurring the event $\mathrm{A}$ and the total number $n$ of the experimental results considered equally possible (all the results are possible):

$$
P(A)=\frac{m}{n}
$$

Where:

$m=$ number of favourable results for occurring the event A

$n=$ total number of experimental results considered equally possible (all results are possible)

The impact of the risk indicates the effect of the risk on the organization's objectives if it is manifested. The probability and the impact of the risk are assessed as:

$>$ High,

$>$ Moderate,

Low.

To perform the matrix of the risk score, we use to calculate the risk score the following formula:

\section{Risk Score $=$ Probability $x$ Impact}

To determine the scores for each risk, the matrix of the risk score is drawn up according to table 1 . 
Matrix of the risk score

\begin{tabular}{|c|c|c|c|c|c|}
\hline \multirow{2}{*}{ Probability } & \multicolumn{5}{|c|}{ Impact of the risk } \\
\cline { 2 - 6 } & $\mathbf{0 . 0 5}$ & $\mathbf{0 . 1}$ & $\mathbf{0 . 2}$ & $\mathbf{0 . 4}$ & $\mathbf{0 . 8}$ \\
\hline $\mathbf{0 . 9}$ & 0.045 & 0.09 & 0.18 & 0.36 & 0.72 \\
\hline $\mathbf{0 . 8}$ & 0.04 & 0.08 & 0.16 & 0.32 & 0.64 \\
\hline $\mathbf{0 . 7}$ & 0.035 & 0.07 & 0.14 & 0.28 & 0.56 \\
\hline $\mathbf{0 . 6}$ & 0.03 & 0.06 & 0.12 & 0.24 & 0.48 \\
\hline $\mathbf{0 . 5}$ & 0.025 & 0.05 & 0.1 & 0.2 & 0.4 \\
\hline $\mathbf{0 . 4}$ & 0.02 & 0.04 & 0.08 & 0.16 & 0.32 \\
\hline $\mathbf{0 . 3}$ & 0.015 & 0.03 & 0.06 & 0.12 & 0.24 \\
\hline $\mathbf{0 . 2}$ & 0.01 & 0.02 & 0.04 & 0.08 & 0.16 \\
\hline $\mathbf{0 . 1}$ & 0.005 & 0.01 & 0.02 & 0.04 & 0.08 \\
\hline
\end{tabular}

Score $<0.05$ - low impact (green)

$0.05 \leq$ Score $<0.15$ - moderate impact (yellow)

Score $\geq 0.15$ - high impact (red).

Quantitative analysis aims the numerical evaluation of the probability and the impact of each risk on the organization's objectives.

By using this method the decisions and the random events are represented as they are perceived by the decision makers.

\section{Conclusions}

It can be concluded that these decisions, which we assign to the category of market decisions, are closely linked to the enterprise development policy and its decisions on production. It is well known that the competitiveness is the most important for maintaining any company on a certain market. Although it has a complex content, the term designates primarily the quality of work, closely related to the quality of workers. That is why it is considered that these decisions are very important for the company.

Because the relative expectations of the decision makers in the decisionmaking environment are subjective, they will perceive degrees of uncertainty differently. Two decision makers can analyse the same event and have different personal expectations (materialized in the subjective probabilities) on the occurrence of the certain events. The procedure of decision making depends largely on the degree of uncertainty perceived by the decision maker. In terms of risk and uncertainty, the typical problem of decision is complex enough to enable a number of possible outcomes for each strategy, results often depending on conditions beyond the control of the decision maker. For this reason, the decision-making methods and techniques constitute a useful tool in presenting and analysing these results, which help the decision-makers to conceptualize and formalize the 
decision-making process with a view to: setting the goals, and the consequences of the decision-making variants, assessing and selecting the alternative strategies. Unfortunately, many managers do not think in the incremental terms; they make decisions based on the average values of the total costs, in the most cases these short-term decisions proving to be incorrect because the goal of the company is to maximize the profits.

Decision trees are a technique applicable to both classification and prediction, the result taking the form of a tree that has a hierarchy of logical rules set automatically by exploring a database of examples. Examples have the form of records consisting of several attributes. Rules are obtained as a result of a more and more detailed subdivision of the examples, according to the content of the attributes.

Decision trees are proven to be particularly useful for deciding on financial or numbers, where a large amount of complex information must be taken into account.

They provide an effective structure in which alternative decisions and the implications of their choice can be assessed, and help the formation of fair, balanced risks and rewards arising from certain choices.

\section{References}

- Adair, J.E. (2010), Decision Making and Problem Solving Strategies: Learn Key Problem Solving Strategies; Sharpen Your Creative Thinking Skills; Make Effective Decisions (Sunday Times Creating Success), Kogan Page Publishers.

- Bondrea, A.A., Gârdan, D.A., \& Geangu, I.P. (2010). The role of strategic planning in relationship marketing. Annals of Spiru Haret University, vol. 1(10), issue 4: 53-60.

- Braga V. (2008), Tabloul de bord, instrument managerial, Annals of the “Constantin Brâncuşi” University, Târgu Jiu, no. 1.

- Raţiu-Suciu C. (2007), Modelare economică, Bucharest: ASE Publishing House.

- Tofan C. A. (2009), Data base concerning the costing management, Annals of Spiru Haret University, Economic Series, issue XV: 49-54.

- Tofan C. A. (2009), The management of the informatics systems projection, Review of General Management, Braşov, vol. 10(2): 40-49.

- Tofan C. A. (2013), Information system - a component of the management system, Review of General Management, Spiru Haret University, Faculty of Management Braşov, vol. 17, issue 1: 188-194.

- Zaccaro E. (2006), Becoming a Problem Solving Genius: A Handbook of Math Strategies, Bellevue, Iowa: Hickory Grove Press.

- Zeitz P. (2008), The Art and Craft of Problem Solving, New York: John Wiley. 